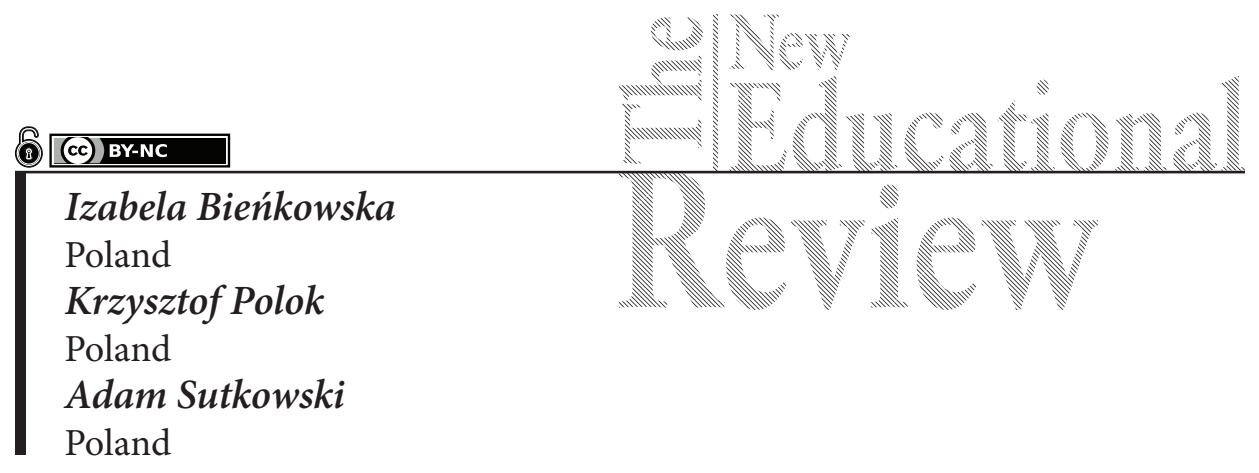

\title{
Making Language Teachers Creative; Teaching English in Elementary Mainstream Schools with Integration Classes
}

DOI: 10.15804/tner.2020.59.1.08

\begin{abstract}
This article tries to examine the influence of using creative methods of teaching English on the language competency of Special Educational Needs (SEN) learners in mainstream Elementary Schools with integration classes in Poland. We questioned 64 English teachers working in such facilities throughout Poland. In the course of the research, we have proved the hypothesis that using creative techniques and approaches enhances growth of SEN learners' language competency in an integration environment. Statistical tools are used to test answers to research questions. The first question measures the correlation between age, gender and seniority with the attitude towards implementing creative approaches, while the second concerns aspects of a creative teacher.
\end{abstract}

Key-words: creativity, creative teachers, SEN learners, Mainstream schools, Integration Classes.

\section{Introduction}

In recent years, the growing number of Special Educational Needs (SEN) learners that are allowed to enter mainstream education forced policymakers to include such learners into the functioning system, thus allowing them to achieve educational goals. Although there are special education facilities, SEN learners want to be a part of mainstream schools. The Polish educational system introduced 
mainstream schools with integration classes in order to guarantee a chance for disabled learners to become valuable members of society. As, following Hulek's (1987) claim, Integration Classes are visible exclusively in Poland, there is a need to investigate this phenomenon, especially from the perspective of lessons of English as a foreign language. What is more, given the numerous studies conducted throughout the world (cf. Albert \& Kormos, 2004; Dacey, 2011), English teachers in the aforementioned schools have been reported to be given an opportunity to introduce creativity into their classrooms. With this idea in mind, this paper tries to measure teachers' attitude to incorporating creative approaches to the teaching of English and the likelihood of English language competence growth of SEN learners.

This study aims to fill the gap in the research on Integration Classes. Most of the existing studies discussing various aspects on ELT/ELL are not designed for the Polish integration environment. However, they shed light on the importance of incorporating creativity while working with FL learners (SEN learners included). What is more, the studies emphasise the complexity of the term "creativity" as each possesses their own view on the topic.

\section{Theoretical background}

Several contemporary scholars (cf. Jones \& Richards, 2016; Runco \& Jaeger, 2012) agree that creativity cannot be defined without the notion of novelty. Moreover, each branch of science, without exception, supports novelty, and this is visible in its definition of creativity. Nonetheless, this notion is not the only component of pure creativity. Apart from novelty, a creative act incorporates relevance and effectiveness. The former represents the necessity to conduct such an act. In terms of education, this means that the teacher's creativity has to correspond with his/ her learners' proficiency.

Having examined the similarities and differences among scholars regarding creativity, a standard definition of creativity can be formulated. Scholars' implications may use different vocabulary, but they relate to the same ideas. Throughout the $20^{\text {th }}$ century, when scholars identified creativity as a scientific phenomenon, each paper on creativity included its own definition of the term. Therefore, a standard definition of creativity demands originality and effectiveness. According to Runco \& Jaeger (2012), who have analysed numerous definitions of creativity in their 2012 article on standard definitions, Barron (1955) and Stein (1953) should be cited whenever such standard definitions are used. However, the one that especially fits 
here could be the one offered by Torrance (1965, p. 663), who sees creativity as "the process of becoming sensitive to problems, deficiencies, gaps in knowledge (...); identifying the difficulty; searching for solutions (...) or formulating the hypotheses; testing and retesting these hypotheses (...) and finally communicating the results."

The main reason for this paper is to support the idea that creative techniques and approaches regarding disabled students within mainstream education need to be introduced into the EFL classroom. Following Dacey (2011, p. 610), there is scarcely any evidence that disabled learners are less susceptible to creativity in comparison to regular leaners. On the other hand, the same scholar observes that there is little research done on creative approaches to teaching English learners with various disabilities.

Hulek (1987) created the foundations of contemporary integrated education in Poland. His views are visible in the legislation and implementation of this form of education in Polish schools, including the idea of equal educational opportunities for all students, regardless of their economic status or health. His pedagogical implications required adaptation of content, methods and changes in the organization of work and forms of education to the educational needs and development opportunities of each student participating in this process. Integration, although in its essence playing an important role, carries some risks, including those related to the implementation of the core curriculum'.

Ideally, mainstream schools with integration classes exercise the main ideas of partial integration to the core-curriculum. Their structure is meant to support not only SEN learners, but also their parents and the local community. An assistant teacher is present in every lesson of an integration class in order to aid SEN learners. What is more, each mainstream school with integration classes provides a spectrum of specialists committed to SEN learners. Hulek (1987) concludes that in order for genuine integration to occur, a SEN learner has to be a full and equal member of a class.

The central idea behind introducing integration classes is to allow all the learners to learn according to the same curriculum as the rest of the class. Therefore, they all use the same course-books, and the only difference between the learners

${ }^{1}$ In the Polish education system, learners who have an opinion from a psychological and pedagogical counselling centre implement at least the minimum core curriculum, whereas the learners with a judgment issued also by the mentioned-above counselling centre must have adaptations that take into account their type of disability and psychophysical abilities. Both groups of learners are classified as SEN are covered by psychological and pedagogical assistance in the facility. 
is the pace of learning. Thanks to the high number of specialists in each Elementary School with Integration Classes, SEN learners are provided with guidelines to help them meet educational goals. Each of them has a meticulously prepared individual plan based on an opinion from a psychological counselling centre. The plan includes all of the additional classes and revalidation classes which are crucial in SEN learners' knowledge growth.

Mainstream Elementary Schools with Integration Classes are not only the first stage of integrating SEN learners with regular members of the community, but also the teachers working in such facilities have a strong impact on SEN learners. Such learners spend almost half of each weekday at school so the more they gain at school, the better members of society they can become.

Even though Polish scholars (e.g. Hulek, 1987) published a few works about incorporating SEN learners into the classroom, there is still a lack of works on SEN learners in English classrooms within the Polish mainstream school system (especially schools with integration classes). This paper aims at filling that void by researching teachers' perspectives. It is our theory that the teacher as a creative facilitator of the lesson plays an important part in introducing new material. In this way, the successfulness of such an educational process may be determined by the level of creativity that an educator is willing to awake in disabled learners.

In the course of this paper, since creativity is said to be unmeasurable (cf. Jones \& Richards, 2016, p. 3) and the source of it can be as well inborn as developed through training or courses, its various instances in educational life are meant to be analysed.

\section{Methodology}

The primary purpose of the research concentrates on discovering and developing creative approaches to teaching English students with various disabilities in Mainstream Elementary Schools with Integration Classes. While investigating this phenomenon, we tried to analyse the following hypotheses.

H0: Creative approaches to teaching English do not enhance the general English performance of disabled students.

H1: Creative approaches to teaching English enhance the above-mentioned performance of disabled students.

During the analysis, two variables are to be cross-referenced with the findings. The dependent variable is the fact that all of the subjects interviewed are teachers 
who work in an Elementary Mainstream School with Integration Classes, and the independent variable is age, gender, and teaching seniority.

Creativity is a complex term itself and combined with a disability makes it a growing subject in the contemporary classroom; this makes room for research regarding these two issues merged together. There is only a handful of papers regarding both matters (cf. Bogdan \& Biklen, 2007, Albert \& Kormos, 2004); thus, our research may expand understanding in this area.

In order to achieve precise answers, it was decided to use a semi-structured Likert scale questionnaire; additionally, each of the research participants was requested to answer a few precisely formatted interview-like questions, asked in the form of online interviews carried out with each of the research participants (all together 64 teachers of English). The above-mentioned online interviews mostly focused upon the conditions of work of the teachers, as well as their attitude to creative forms of lesson design. Both sections of the mixed research were aimed to help us discover answers to the following research questions:

RQ1: Is there a correlation between age, gender and years of experience as an English teacher and the attitude towards creativity?

RQ2: What are the aspects of a creative teacher?

The research is designed for teachers who work in Elementary Mainstream Schools with Integration Classes. All the participants, who work various schools in Poland, declared they had graduated from universities and received numerous forms of special training; this declaration is hoped to guarantee the objectivity and validity of the research, despite the probable likeness of the information provided by the research participants.

\section{Results}

In the course of the study, 64 teachers of English, 52 females (81\%) and 12 males (19\%), were asked to complete the questionnaire; subsequently, they were also requested to take part in online interview. All of them work in Mainstream Elementary School with Integration Classes throughout Poland. We selected participants of different ages and with different teaching experience to give a varied sample.

We have separated experience in working in Mainstream Elementary School with Integration Classes from overall teaching experience (Fig. 1 and Fig. 2). We could observe a significant disparity in experience between male and female teachers, which is analysed later in the paper. 


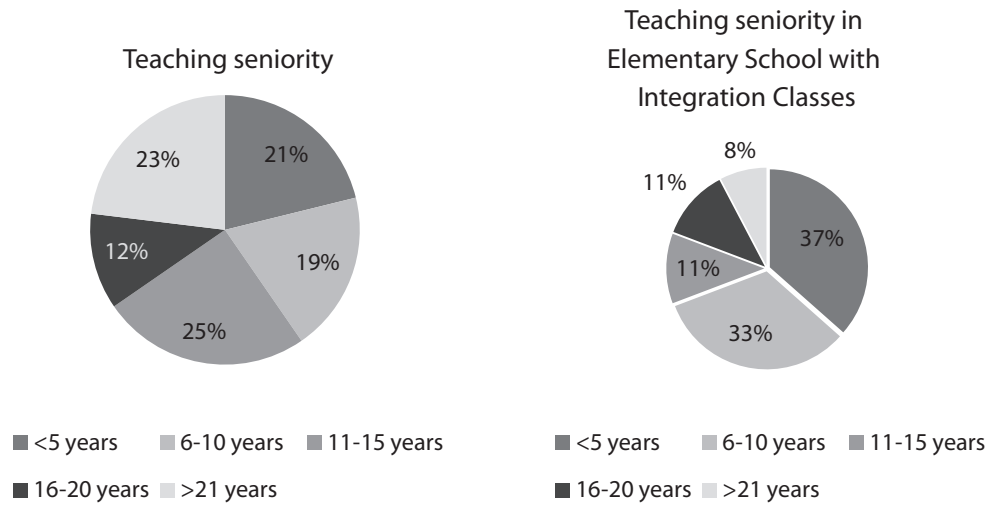

Fig. 1. Years of teaching experience among female participants (own work)

Following the results presented in Fig. 1. and Fig. 2., the overall teaching seniority of female interviewees does not change practically, whereas the study almost lacks male participants with more than twenty years of experience. What is more, none of the male subjects have worked in Elementary School with Integration Classes longer than fifteen years.

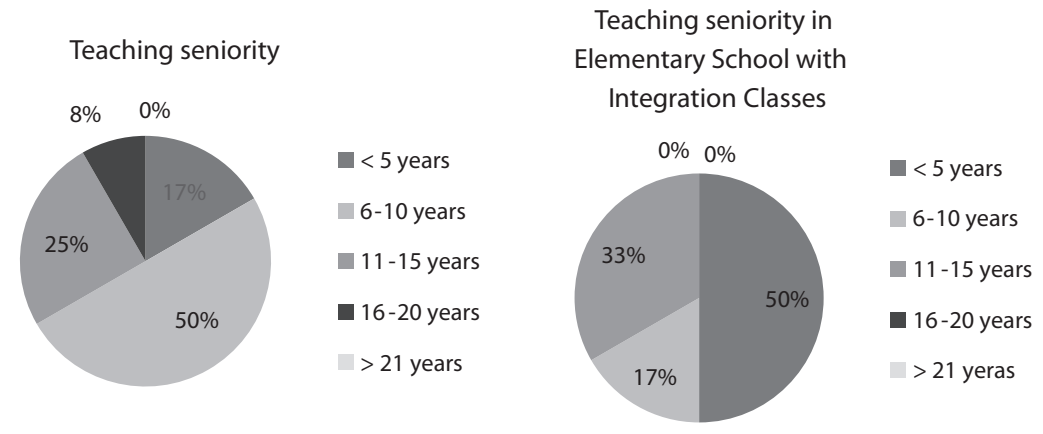

Fig. 2. Years of teaching experience among male participants (own work)

The third and final variable is age. One of the RQs touches upon the correlation of age, teaching seniority, and the educator's level of creativity. The participants are assigned to one of five age groups (Fig. 3).

Among 64 teachers that took part in the study, only four are at the threshold of their professional careers. The most numerous group contains relatively experienced teachers aged between thirty-one and forty ( $40.6 \%$ of the respondents). 


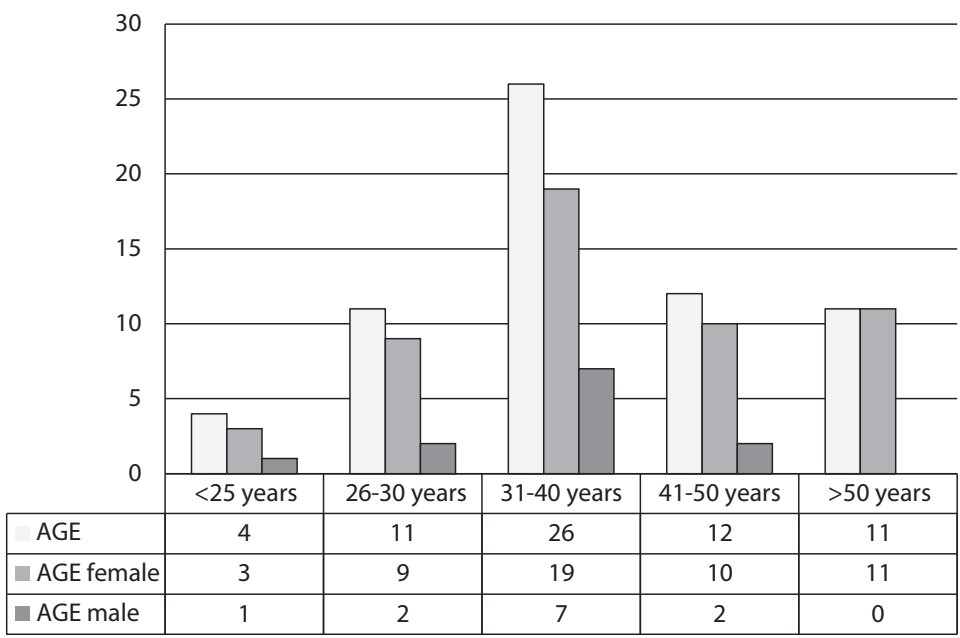

Fig. 3. Age diversity between female and male participants (own work)

\section{The hypothesis}

In order to deduce if to accept or reject the null hypothesis, we combined statistical tools with both independent and dependent variables. Among the independent variables, we tested age and gender, while dependent variables were measured by questions regarding teaching seniority, teaching seniority working with disabled students and how respondents perceive their own personal and professional creativity.

Table 1. Pearson's $r$ correlation calculations for the hypothesis (own work)

\begin{tabular}{c}
$\begin{array}{c}\mathrm{X} \text { Values } \sum=261 \mathrm{Mean}=4.078 \sum(\mathrm{X}-\mathrm{Mx}) 2= \\
\mathrm{SSx}=42.609\end{array} \begin{array}{c}\text { Y Values } \sum=255 \mathrm{Mean}=3.984 \sum(\mathrm{Y}-\mathrm{My}) 2= \\
\mathrm{SSy}=48.984\end{array}$ \\
\hline $\mathrm{X}$ and $\mathrm{Y}$ Combined $\mathrm{N}=64 \sum(\mathrm{X}-\mathrm{Mx})(\mathrm{Y}-\mathrm{My})=33.078$ \\
\hline $\mathrm{R}$ Calculation $r=\sum((\mathrm{X}-\mathrm{My})(\mathrm{Y}-\mathrm{Mx})) / \sqrt{ }((\mathrm{SSx})(\mathrm{SSy})) r=33.078 / \sqrt{ }((42.609)(48.984))=0.724$ \\
$r=0.724$-value $<0.001$
\end{tabular}

64 teachers of English, working in Elementary Mainstream Schools with Integration Classes were asked whether SEN learners appreciate using creative approaches during the lesson. To measure their responses, a Likert five-point scale was implemented (from 1 - strongly disagree to 5 - strongly agree). Having calcu- 
lated the results of RQ1, being the basis for proving the hypothesis, we arrived at the following results: $\mathrm{Mx}=4.08$ and $\mathrm{SDx}=0.85$. The second question asked for their opinions about whether the successfulness of using creative approaches leads to the language competency growth of SEN learners. The five-point Likert scale gave the values of: $\mathrm{My}=3.98$ and $\mathrm{SDy}=0.93$.

Table 2 presents the calculations for the hypothesis where $\mathrm{X}$ values represent teachers' opinion on the appreciation of creative approaches during the lesson while $\mathrm{Y}$ values represent teachers' views on the belief that successfulness of such approaches leads to learners' language competency growth.

Pearson's $r$ data analysis revealed a moderate positive correlation $(r=0.724$ with $p$-value $<0.001)$. Taking this into consideration, we accept $\mathrm{H} 1$, that according to the teachers using creative approaches enhances SEN learners' language competence. Consequently, the null hypothesis is rejected as the correlation is closer to the highest possible value with the significance level at $\mathrm{p}$-value $<0.001$. (Table 1.)

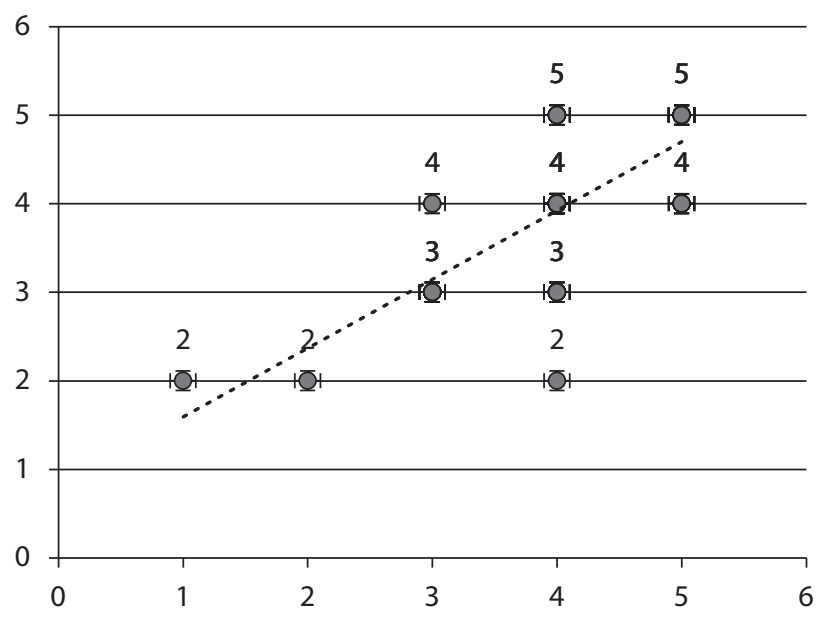

Fig. 4. Linear representation of Pearson's $r$ correlation regarding the hypothesis (own work)

According to Fig. 4, the results rise with the responses to the questions. Therefore, the hypothesis proves that the higher the appreciation of incorporating creative methods, the higher the SEN learners' language competency growth. What is more, the general tendency of the respondents that creative lessons enhance the process of gaining knowledge promotes the notion of incorporating creative approaches as a means to strengthen SEN learners' performance during the English lesson. 


\subsection{Analysis of RQ1}

In order to determine statistically valid data, Pearson's $r$ is used to facilitate the answer connected with RQ1. This shows that there is a weak correlation between interviewees' age, gender, teaching seniority and their level of creativity (Table 2). The table is divided into twelve sections which analyse different variables. Such design of weighing the data allows us to fully understand the differences between each of the aspects analysed in RQ1.

The conclusion that we draw upon the results of RQ1 is that the level of personal as well as professional creativity is not implied by any factor measured in the study. Therefore, these aspects cannot be taken into consideration while assessing the influence of personal features on the level of creativity. The results are mainly insignificant, as the $p$-value varies from .302 when age and personal level of creativity are analysed to .671 in the correlation between gender and personal creativity.

Table 2. Pearson's r correlation for key features of RQ1 (own work)

\begin{tabular}{|c|c|c|c|}
\hline $\begin{array}{l}\text { Correlation of age } \\
\text { and being a creative } \\
\text { person }\end{array}$ & $\begin{array}{c}\text { Correlation of age } \\
\text { and being a creative } \\
\text { teacher }\end{array}$ & $\begin{array}{l}\text { Correlation of gender } \\
\text { and being a creative } \\
\text { person }\end{array}$ & $\begin{array}{c}\text { Correlation of gender } \\
\text { and being a creative } \\
\text { person }\end{array}$ \\
\hline $\begin{array}{l}\mathrm{r}=-0.1312 \text { The } P \text {-val- } \\
u \text { is } .302166 . \text { The } \\
\text { result is not signifi- } \\
\text { cant at } \mathrm{p}<.05 \text {. }\end{array}$ & $\begin{array}{l}\mathrm{r}=-0.3135 \text { The } P \text {-val- } \\
u \text { is } .011793 \text {. The } \\
\text { result is significant at } \\
\mathrm{p}<.05 .\end{array}$ & $\begin{array}{l}\mathrm{r}=0.0541 \text { The } P \text {-value } \\
\text { is } .671142 \text {. The result } \\
\text { is not significant at } \mathrm{p} \\
<.05 \text {. }\end{array}$ & $\begin{array}{l}\mathrm{r}=-0.0594 \text { The } P \text {-val- } \\
u \text { is } .643292 . \text { The } \\
\text { result is not signifi- } \\
\text { cant at } \mathrm{p}<.05 \text {. }\end{array}$ \\
\hline $\begin{array}{l}\text { Correlation of } \\
\text { teaching seniority } \\
\text { and being a creative } \\
\text { person }\end{array}$ & $\begin{array}{l}\text { Correlation of } \\
\text { teaching seniority } \\
\text { and being a creative } \\
\text { teacher }\end{array}$ & $\begin{array}{l}\text { Correlation of teach- } \\
\text { ing seniority in Ele- } \\
\text { mentary School with } \\
\text { Integration Classes } \\
\text { and being a creative } \\
\text { person }\end{array}$ & $\begin{array}{l}\text { Correlation of teach- } \\
\text { ing seniority in Ele- } \\
\text { mentary School with } \\
\text { Integration Classes } \\
\text { and being a creative } \\
\text { teacher }\end{array}$ \\
\hline $\begin{array}{l}\mathrm{r}=-0.1093 \text { The } P \text {-val- } \\
\text { ue is } .391239 . \text { The } \\
\text { result is not signifi- } \\
\text { cant at } \mathrm{p}<.05 \text {. }\end{array}$ & $\begin{array}{l}\mathrm{r}=-0.2624 \text { The } P \text {-val- } \\
\text { ue is } .036495 . \text { The } \\
\text { result is significant at } \\
\mathrm{p}<.05 .\end{array}$ & $\begin{array}{l}\mathrm{r}=-0.1114 \text { The } P \text {-val- } \\
\text { ue is } .382554 \text {. The } \\
\text { result is not signifi- } \\
\text { cant at } \mathrm{p}<.05 \text {. }\end{array}$ & $\begin{array}{l}\mathrm{r}=-0.2652 \text { The } P \text {-val- } \\
\text { ue is } .034327 . \text { The } \\
\text { result is significant at } \\
\mathrm{p}<.05 .\end{array}$ \\
\hline
\end{tabular}

On the other hand, statistically significant correlations concerning the subjects of the study appear in three (out of eight) instances measured in the course of the analysis. The first is the relationship between age and being a creative teacher, where $r=-0.3135$ with $p$-value as .011793 . Such a result indicates that the level of professional creativity decreases with age. The second valid correlation appears in the correlation of teaching seniority and being a creative teacher where $r=-0.2624$ 
while the $p$-value is .036495 . The result is significant at $p<.05$ and shows that there is a mild negative correlation between the two aspects. The last statistically relevant correlation is between teaching seniority in Elementary School with Integration Classes and being a creative teacher. There $r=-0.2652$ and the $p$-value is .034327 . Analogically to the previous instance, a mild negative correlation is visible in the sample tested in the course of the research.

\subsection{Analysis of RQ2}

The main aim of RQ2 is to produce a set of the attributes of a creative teacher. Each respondent was presented online with five statements that could describe a creative teacher. They could either choose as many statements as they preferred or provide their own. Unfortunately, none of the respondents chose to provide additional input. Another aspect analysed was the attitude towards each statement separately. The questionnaire used a five-point Likert scale to determine the results.

Table 3. Aspects of a creative teacher according to the respondents (own work)

\begin{tabular}{lcc}
\hline \multicolumn{1}{c}{$n=\mathbf{6 4}$} & $\begin{array}{c}\text { The number of } \\
\text { respondents that } \\
\text { chose the answer. }\end{array}$ & $\begin{array}{c}\text { The average } \\
\text { score of each } \\
\text { statement }(5= \\
\text { strongly agree) }\end{array}$ \\
\hline 1. Creative teacher guides classes enthusiastically. & $48(75 \%)$ & 4.19 \\
\hline 2. Creative teacher does not impose rules. & $6(9.4 \%)$ & 2.29 \\
\hline $\begin{array}{l}\text { 3. Creative teacher has security and scientific compe- } \\
\text { tence. }\end{array}$ & $36(56.2 \%)$ & 3.89 \\
\hline 4. Creative teacher is a friend of the students. & $24(37.5 \%)$ & 3.28 \\
\hline 5. Creative teacher promotes student autonomy. & $54(84.4 \%)$ & 4.28 \\
\hline
\end{tabular}

According to Table 3, there are two predominant features of a creative teacher. The opinion that the creative teacher promotes student autonomy is favoured by $84.4 \%$ of the respondents, and creative teacher guides classes enthusiastically are named by $75 \%$. To support the importance of these two features we looked at the interviewees' attitudes towards the statement. The average score of the former option is 4.19 while the latter has an average of 4.28.

What is more, the teacher's pedagogical competence is another major factor as the majority $(56.2 \%)$ of respondents accept this feature as a vital one. Forty interviewees see the necessity of drawing a line between the teacher and a learner, since they do not choose to be a learner's friend as a crucial aspect in becoming a creative teacher. The least favoured response is lack of teacher-imposed rules 


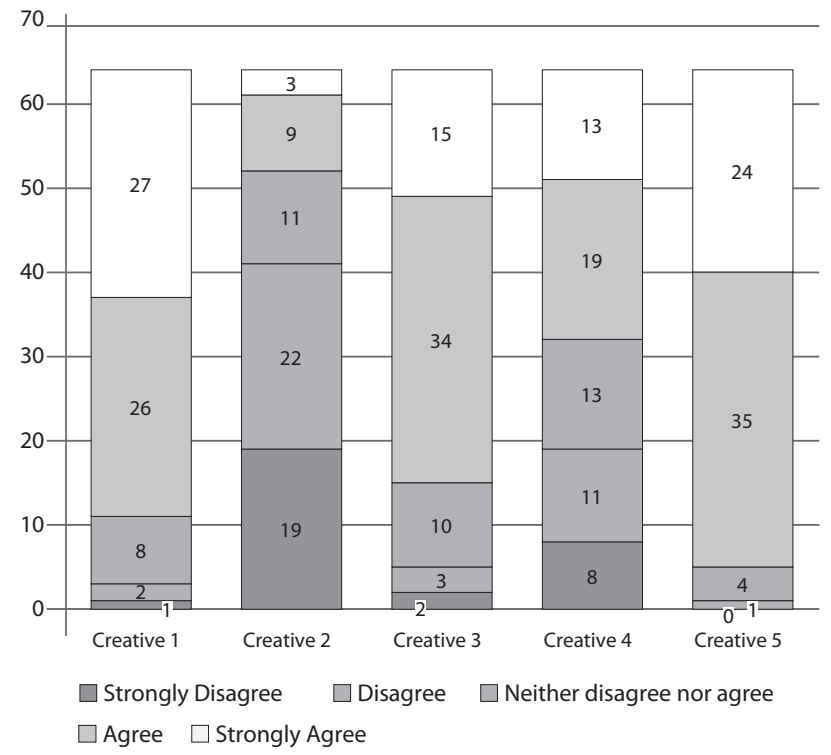

Fig. 5. Division of responses to the five statements regarding creative teachers (own work)

in a creative environment. Only six teachers named it as essential and the overall average of attitude towards the statement is only 2.29 , which means that the majority of respondents disagrees with it.

Fig. 4 presents detailed results to the five statements. The diversity within the answers to each statement is visible for every statement. As mentioned above, statements one, three and five depict the respondents' positive attitudes towards views provided in the questionnaire. What is more, the respondents are aware of the importance of maintaining order in the classroom in order to conduct a lesson successfully, as 19 of the respondents strongly disagree with the statement that a creative teacher does not impose rules.

While analysing the data provided by the teachers who took part in the whole study, we reject the null hypothesis and accept the alternative hypothesis. Therefore, the main aim of the thesis is achieved. The fact that according to teachers incorporating creative approaches into the English classroom in Polish Mainstream Education system leads to the English competency growth of SEN learners supports our belief that creativity is the key to successful learning and teaching.

In the course of the study, the answers to the four RQs are scrutinised and provide a deep insight into the teacher's mind. Moreover, the teacher's role as 
a facilitator of the lesson is visible, in particular in an integration environment which concludes our study as scientifically accurate and pedagogically meaningful.

\section{Concluding Remarks}

This paper provides its reader with an insight into the Mainstream Elementary School with Integration Classes, a specific environment that can be observed in such a school and the vital role of the teacher in shaping young learners. What is more, we provide a comprehensive description of various aspects of creativity that can influence the lesson.

The study has accomplished all the aims that we formulated at the beginning of the research. We accept the hypothesis stated in the thesis. In the course of the study, we proved that creative approaches to teaching English are not only are useful but according to teachers also enhance the SEN learner's competence and language growth.

What is more, we are satisfied with the results to all the research questions. The results to RQ1 suggest that creativity is such a personal feature that it is not embedded in any variable measured in the study. Each can influence and facilitate creativity. What is more, when it comes to teachers, they, as professionals, carry all the necessary tools to implement creativity in the classroom.

The results regarding RQ2 unearthed the fundamental aspects of a creative teacher. The results correspond with our personal opinion of such a person, as the statements regarding a lack of teacher-imposed rules in a creative environment played the role of a false agent. During the online interviews the respondents agreed with us that the requirements for creative English teachers are universal and, apart from pedagogical expertise, they evolve around the teacher-student relationship.

Throughout the process of designing the thesis, the main objective remained the same. Teachers as a major force in shaping young learners ought to have a firm foundation to be able to achieve educational goals. Moreover, SEN learners deserve the same appreciation. The outcome of the research proves that teachers are aware of SEN learners' needs and the limitations they are faced with when working with them. What is more, teachers provide a thorough insight into the educator's mindset and the qualities one ought to possess while working within the integration class. 


\section{Suggestions for Further Research}

Although the researchers covered a broad spectrum of views on creativity within the English classroom, we suggest that the field needs further research in this area. 64 respondents interviewed online in the study are a limited group. So as to meet the expectations of nowadays society much broader and more comprehensive selection is needed. The fact that SEN learners do not always choose to attend Mainstream Elementary School with Integration Classes and the notion of inclusion in education suggest that integration classes may not be the sole environment for incorporating SEN learners into the mainstream education system. Studies on this notion are crucial to assess the importance of this switch in trends.

\section{References}

Albert, A. \& Kormos, J. (2004). Creativity and narrative task performance: An exploratory study. Language Learning, 54, 277-310.

Barron, F. (1955). The disposition towards originality. Journal of Abnormal and Social Psychology, 51, 478-485.

Bogdan, R.C. \& Biklen, S.K. (2007). Qualitative research for education: An introduction to theories and methods. Boston, MA: Pearson.

Dacey, J. (2011). Historical Conceptions of Creativity. In: M. Runco \& S. Pritzker (eds.) Encyclopedia of Creativity. Second Edition (pp. 608-616). Cambridge, Massachusetts: Academic Press.

Hulek, A. (ed.) (1987). Integracja społeczna ludzi niepetnosprawnych. Zadania Pedagoga. [Eng: Social Integration of the Disabled People. A Teacher's Tasks]. Wrocław, Poland: PAN.

Jones, R. \& Richards, J. (2016).Creativity in language teaching. Perspectives from Research and Practice. London, Routledge.

Runco, M.A. \& Jaeger, G.J. (2012). The Standard Definition of Creativity, Creativity Research Journal, 24, 92-96.

Torrance, P. (1965). Creativity and Learning. Deadalus, 94/3, 663-681. 